\title{
Sero-Prevalence of HBV, HCV and HEV among the Egyptian Pregnant Females
}

\author{
Suzan Samir Elsharkawy* ${ }^{\circledR}$, Wael Samir Elgazayerli \\ Lecturer at Department of Obstetrics and Gynecology, Faculty of Medicine, Alexandria University, Alexandria, Egypt \\ Email: `S_Abdelrahim00@Alexmed.edu.eg,waelelg azayerli1010@g mail.com
}

How to cite this paper: Elsharkawy, S.S. and Elgazayerli, W.S. (2019) Sero-Prevalence of HBV, HCV and HEV among the Egyptian Pregnant Females. Open Journal of Obstetrics and Gynecology, 9, 1429-1438. https://doi.org/10.4236/ojog.2019.910138

Received: September 9, 2017

Accepted: October 9, 2017

Published: October 25, 2019

Copyright $\odot 2019$ by author(s) and Scientific Research Publishing Inc. This work is licensed under the Creative Commons Attribution International License (CC BY 4.0).

http://creativecommons.org/licenses/by/4.0/ (c) (i) Open Access

\begin{abstract}
Background: Viral hepatitis in pregnant women can be caused by multiple types of hepatitis viruses and can cause a wide range of symptoms and complications, ranging from asymptomatic infection to maternal and fetal deaths. Objective: The aim of this study was to evaluate the sero-prevalence and the associated factors of viral hepatitis B (HBV), viral hepatitis C (HCV) and viral hepatitis E (HEV) among the Egyptian pregnant females. Methods: This cross-sectional study was conducted in the period from January to July 2017 in two selected antenatal clinics; El-shat by maternity university hospital at Alexandria city and El-Behera health insurance antenatal clinic at Damanhur city on 261 apparently healthy gravid women. Eligible women were evaluated by a questionnaire about socio-demographic data and viral serological tests were done at El-shat by maternity University Hospital Laboratory. Results: The overall HBs-Ag sero-prevalence in the pregnant women included in this study was 7 cases $(2.7 \%)$ and HCV-RNA PCR was 4 cases (1.5\%). Of the total study participants, none of them (0\%) were anti-HEV IgM positive and 48 cases (18.4\%) were anti-HEV IgG positive. According to our results, neither age of the woman, place of residence, past family history of hepatitis virus infection nor having a pet animal had any strong association to be considered as an associated factor for acquiring HEV infection. Conclusion: Although it seems that there are many improvements in the prevalence of different hepatitis viruses in the country, hepatitis viral infections are still high enough to continue their preventive programs and health education, to protect the mothers and their fetuses from the hazardous effects of these serious infections.
\end{abstract}

\section{Keywords}

Viral Hepatitis, Hepatitis B Virus, Hepatitis C Virus, Hepatitis E Virus, Pregnant Women 


\section{Introduction}

Many studies discussed the impact of viral hepatitis in pregnant women, as it can be caused by multiple types of hepatitis viruses and can cause a wide range of symptoms and complications, ranging from nothing up to maternal deaths [1].

Noteworthy, these different outcomes can be specified to certain geographical areas, for example, there were no increased mortalities related to hepatitis $\mathrm{E}$ infection among Egyptian and south Indian women [1] [2] while there were reports of higher mortalities from north India [3], despite that all these places are equally endemic for the virus [4].

Each type of hepatitis viruses represents a different entity and should be discussed separately, hepatitis A virus infection does not differ a lot between pregnant and non-pregnant women as it is mainly a feco-oral [1].

Hepatitis B, when acquired near term, can be transmitted vertically in $60 \%$ of cases and causes chronic hepatitis in $90 \%$ of infected newborns, which later on will lead to portal hypertension, liver cirrhosis and hepatocellular carcinoma in the child [5]. Perinatal vertical transmission is the most common mode of transmission of the virus worldwide, as it is estimated that half of the chronically infected individuals worldwide acquired their disease perinatal or early during childhood especially in endemic areas [6] [7]. The higher the maternal viral replication $(\mathrm{HBeAg})$, the greater the risk for vertical transmission will be [8], the risk of virus transmission can be reduced up to $90 \%$ by giving the newborn $\mathrm{HB}$ immunoglobulin with the vaccine within $12-24$ hours of birth [9]. This is why it is essential to screen pregnant women for hepatitis B for identifying the newborns at risk and protect them at the correct time [10].

The average worldwide prevalence of hepatitis $\mathrm{C}$ virus (HCV) infection among pregnant women is around $8 \%$ [11]. The primary mode of HCV transmission is percutaneous exposure to infected blood, other modes include vertical transmission, sharing of contaminated devices, occupational exposure to infected blood and to lesser extent, sexual intercourse [12]. The risk of vertical transmission of HCV is 5.8\% [13]. Maternal HCV infection is associated with increased risk of fetal growth restriction and low birth weight [14]. In 2008, Egypt had the highest burden of hepatitis C virus (HCV) infection in the world, where almost $15 \%$ of the Egyptians were seropositive, $10 \%$ chronically infected, mainly with genotype 4 [15]. In 2015, the sero-prevalence of HCV infection in Egypt has declined to 6.3\% [16] at that time, HCV therapy with Sofosbuvir (Sovaldi $^{\circledR}$ ) was launched in Egypt by Ministry of Health and the Egyptian National HCV Control Program and continued up till now [17].

As regard hepatitis E virus (HEV), it usually causes a benign self-limited hepatitis in men and non-pregnant women, but in pregnancy, it acquires a grave course and may cause fulminant hepatic failure with higher mortality rates than those associated with other viral hepatitis types [18]. HEV can be transmitted vertically [19] and is associated with many adverse fetal and neonatal outcomes 
like; miscarriage, stillbirth, neonatal death and high risk of preterm delivery with poor neonatal survival rates [20]. Hepatitis E virus was first recognized in Asia since 38 years as the main cause of non-A, non-B enterically transmitted hepatitis and the only hepatitis virus that has animal reservoir [21]. It has 7 known genotypes, of which only four genotypes can infect humans [22]. Genotype 1 and 2 are transmitted by fecal-oral route as water borne infection, While Genotype 3 and 4 infections associated with sporadic cases due to consumptions of undercooked meat from infected animals [23]. The current preventive measures primarily aim at reducing risk of exposure to HEV by improving water supply and sewage disposal [24]. HEV Vaccination is an effective prevention strategy, although no commercial vaccine has yet become available for use worldwide [25].

The aim of this study was to evaluate the sero-prevalence and the risk factors of viral hepatitis B (HBV), viral hepatitis C (HCV) and viral hepatitis E (HEV) among the Egyptian pregnant females.

\section{Materials and Methods}

This descriptive cross-sectional study was conducted in the period between January to July 2017 in two selected antenatal clinics; El-shat by maternity university hospital at Alexandria city and El-Behera health insurance antenatal clinic at Damanhur city. Written permissions were also obtained from the Hospital and Health insurance administrators. Sample size was calculated for each health facility according to the number of pregnant women who had their follow up in the clinic using Epi-info at confidence interval 95\%. The study was accepted by the department ethical committee of faculty of medicine and a written informed consent was obtained from each participant before being enrolled in the study. 261 pregnant women (at any gestational age) seeking antenatal care were included in this study. Inclusion criteria were having Egyptian nationality and being apparently healthy. Exclusion criteria were; any chronic or acute illness in general, pre-eclampsia and jaundice. Eligible women were evaluated by a questionnaire about socio-demographic data (age, place of residence, family history of hepatitis virus pet ownership and hepatitis B vaccination status).

Five mille-liters of blood were collected from each participant. Sera were separated at the study clinic sites and transported to El-shatby maternity university Hospital Laboratory and kept at $-20^{\circ} \mathrm{C}$ until processing. Screening for $\mathrm{HBV}$ infection was done by enzyme-linked immunoassay (ELISA) for hepatitis B surface antigen (HBs-Ag) using the AbbottAxSYM System, with sensitivity $97.8 \%$ and specificity 98.1\% (Abbott Laboratories, Abbott Park, Chicago, IL, USA). Screening for HCV was done using ELISA for HCV-Ab (antibodies), with sensitivity and specificity reach almost $99 \%$, and then positive samples were confirmed by using HCV RNA PCR (polymerase chain reaction) test. For detection of HEV (Anti-HEV IgG and Anti-HEV IgM); ELISA was performed on all samples using ELISA Kit, with $97.7 \%$ sensitivity and $96.5 \%$ specificity (WANTAI HEV-Ab 
ELISA, China) [26].

Descriptive analysis of socio-demographic and behavioral characteristics of the study population was done using appropriate measures of central tendencies. Between-group comparisons were done using means, median, or frequencies where appropriate and differences were considered statistically significant at $\mathrm{p}>$ 0.05 . Associations were presented as odds ratios (OR) with $95 \%$ confidence intervals (CI). Data were analyzed using SPSS (version 20) [27].

\section{Results}

Total of 261 cases were screened and evaluated during the study duration from January till July 2017. Their age ranged from 18 to 42 years, with a mean age \pm SD of $29.53 \pm 5.60$ years. Among the study participants, 111 (42.5\%) were from rural residence and 150 (57.5\%) were from urban residency. There were 63 (24.1\%) cases had positive family history of previous hepatitis virus infections and 75 (28.7\%) cases were pet owners, as shown in Table 1.

The overall HBs-Ag sero-prevalence in the pregnant women included in this study was 7 cases (2.7\%). Given the study inclusion criteria, this HBVsAg most likely indicates chronic carrier state "chronic infection". For HCV-RNA PCR was 4 cases (1.5\%). Of the total study participants, none of them (0\%) were anti-HEV IgM positive and 48 cases (18.4\%) were anti-HEV IgG positive. Vaccined women against HBV were $42(16.1 \%)$ cases only, as shown in Figure 1.

Due to the scanty prevalence of HBVsAg, HCV-RNA PCR positive cases and the absence of HEV IgM positive cases in the study participants, we correlated the socio-demographic and behavioral characteristics to HEV IgG positivity to demonstrate any possible risk factors for getting infected by the virus. According to our data, neither age of the woman, place of residence, family history of hepatitis virus infection nor having a pet animal (domestic cats and dogs) had any statistical significance or strong association to be considered as a risk factor for HEV IgG positivity, as shown in Table 2.

\section{Discussion}

Hepatitis viruses' infection is a major public health burden in Egypt, where it bears one of the highest prevalence rates in the world [28]. The overall prevalence in pregnant women is estimated to be declining, this may be due to increasing level of public awareness of the risk factors of infection, increase educational levels of women, vaccination programs for HBV, screening of blood and blood products, improved water supply and sanitary disposal.

There is a great difference in the prevalence of HBV between developed and developing countries. Countries are classified as having low endemic rates $(<2 \%)$, intermediate rates $(2 \%-8 \%)$, or higher endemic rates $(>8 \%)$ positive for HBsAg [29]. Egypt is considered of intermediate endemicity (2\% - 8\%) [30]. In the present study, the sero-prevalence of HBsAg in pregnant women was $2.7 \%$, which agreed with Zahran et al. [31] who had documented a lower prevalence of 
Table 1. Distribution of the studied cases according to demographic data $(n=261)$.

\begin{tabular}{cc}
\hline & No. (\%) \\
\hline Age (years) & $150(57.5 \%)$ \\
$\leq 30$ & $111(42.5 \%)$ \\
Min. - Max. & $18.0-42.0$ \\
Mean \pm SD & $29.53 \pm 5.60$ \\
Median (IQR) & $29.0(26.0-34.0)$ \\
\hline Residence & $111(42.5 \%)$ \\
\hline Rural & $150(57.5 \%)$ \\
Urban & $63(24.1 \%)$ \\
Positive family history & $75(28.7 \%)$ \\
Pet owners &
\end{tabular}

Table 2. Relation between HEV IgG positivity and different parameters.

\begin{tabular}{|c|c|c|c|c|c|}
\hline & \multicolumn{2}{|c|}{ HEV IgG } & \multirow[b]{2}{*}{ OR } & \multirow[b]{2}{*}{$\mathrm{p}$} & \multirow{2}{*}{$\begin{array}{c}\text { 95\% C.I } \\
\text { (L.L - U.L) }\end{array}$} \\
\hline & $\begin{array}{c}\text { Negative }^{(\mathrm{R})} \\
(\mathrm{n}=213)\end{array}$ & $\begin{array}{l}\text { Positive } \\
(n=48)\end{array}$ & & & \\
\hline \multicolumn{6}{|l|}{ Age (years) } \\
\hline$\leq 30^{\oplus}$ & $123(57.7 \%)$ & $27(56.3 \%)$ & \multirow[b]{2}{*}{1.063} & \multirow[b]{2}{*}{0.849} & \multirow[b]{2}{*}{$0.565-1.994$} \\
\hline$>30$ & $90(42.3 \%)$ & $21(43.8 \%)$ & & & \\
\hline \multicolumn{6}{|l|}{ Residence } \\
\hline $\mathrm{Urban}^{\otimes}$ & $123(57.7 \%)$ & $27(56.3 \%)$ & \multirow[b]{2}{*}{1.063} & \multirow[b]{2}{*}{0.849} & \multirow[b]{2}{*}{$0.565-1.994$} \\
\hline Rural & $90(42.3 \%)$ & $21(43.8 \%)$ & & & \\
\hline \multicolumn{6}{|c|}{ Family history } \\
\hline Negative $^{\infty}$ & $159(74.6 \%)$ & $39(81.3 \%)$ & \multirow[b]{2}{*}{0.679} & \multirow[b]{2}{*}{0.336} & \multirow[b]{2}{*}{$0.309-1.493$} \\
\hline Positive & $54(25.4 \%)$ & $9(18.8 \%)$ & & & \\
\hline \multicolumn{6}{|l|}{ Pets } \\
\hline $\begin{array}{l}\text { Negative }^{\infty} \\
\text { Positive }\end{array}$ & $\begin{array}{l}153(71.8 \%) \\
60(28.2 \%)\end{array}$ & $\begin{array}{l}33(68.8 \%) \\
15(31.3 \%)\end{array}$ & 1.159 & 0.670 & $0.587-2.286$ \\
\hline
\end{tabular}

${ }^{\circledast}$ : Reference; OR: Odd’s ratio; L.L: Lower limit; U.L: Upper limit; C.I: Confidence interval.

HBsAg and anti-HCV among pregnant women in Egypt as $4.0 \%$ and $6.4 \%$ respectively. Also EL-Shabrawi et al. [32] showed that the sero-prevelence of HBV was $1.6 \%$ in pregnant Egyptian women.

As regards HCV, The national treatment strategy for control of HCV infection in Egypt that was set by the National Committee for Control of Viral Hepatitis (NCCVH) in 2006 [33], had led to decrease in the viral prevalence from 15\% in 2008 to $6.3 \%$ in 2015 [16]. Our results as regard the prevalence of the virus in gravid women was $1.5 \%$, which agreed with Zahran et al. [31] who explained 


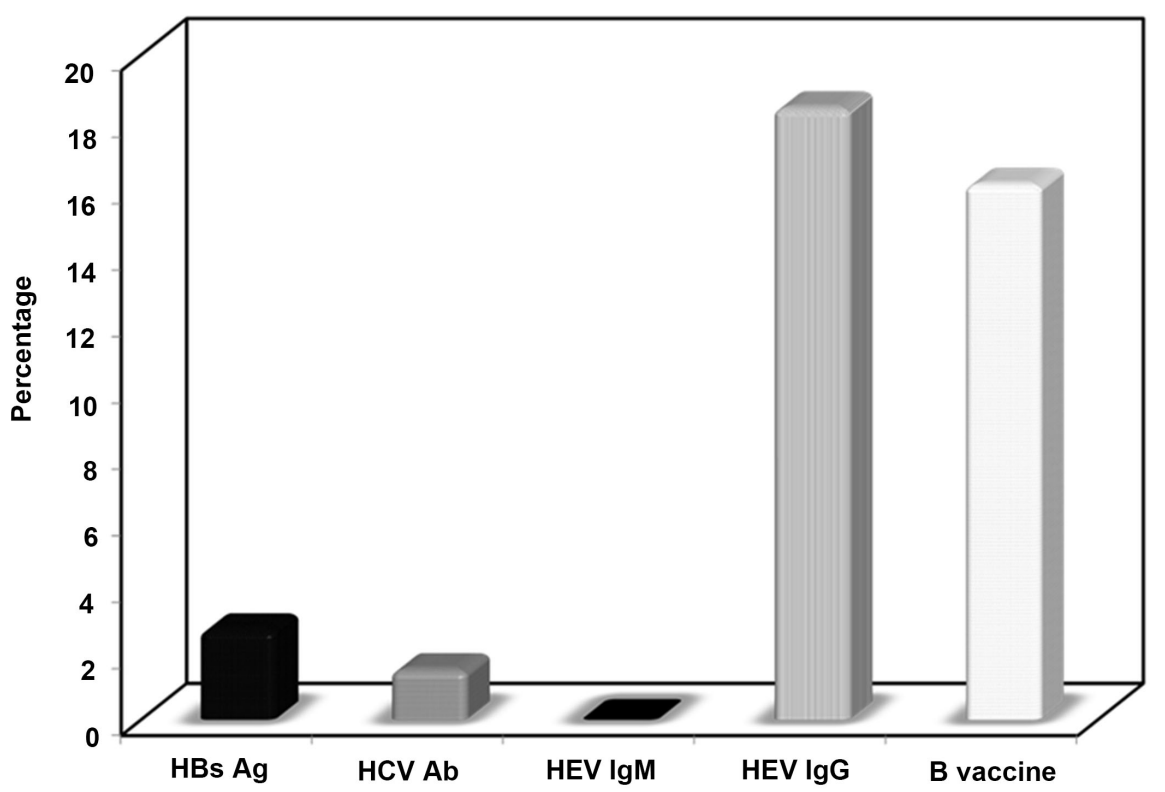

Figure 1. Distribution of the studied cases according to different parameters $(n=261)$.

their results due to decreased rates of female circumcisions that were performed under unsterile circumstances.

Our study demonstrates no cases with acute HEV infections, which may be due to including only the apparently healthy women in our screening. The prevalence of a past HEV infection (before the study period) was detected by the presence of HEV IgG which affected $18.4 \%$ of the cases. This result disagreed with most of the studies done earlier in Egypt, which reported high prevalence of subclinical HEV infection of gravid women, El-Shety G. et al. [34] reported a prevalence of 45\%, 84.3\% prevalence according to Abdel-Hamid et al. [35], and $46.7 \%$ prevalence according to Yahia et al. [36] these improvements may be due to increased health awareness and improved water sanitation across the country.

The prevalence of HEV infection defers across the world, where it is more common in developing than in developed counties [37] [38] [39]. Reason for these differences could be due to different levels of hygiene, education, social status, endemicity of virus and different lifetime exposure to HEV.

In our study, we did not demonstrate any association between age, residency, pet ownership and positive family history with HEV IgG positivity. This may be attributed to the low prevalence of the virus in our participants. Stoszek et al. [2] and Abebe M. [40] showed a strong association between age and HEV seroprevalence, 1.68 times higher risk in pregnant women whose age was $<25$ years. This is most likely reflects cumulative lifetime exposure to the virus. Kafando et al. [41] reported that Anti-HEV reactivity among pregnant women who lived in rural areas was higher than in people of urban residency, and related this to low standards of living and water contamination. Similar to our findings, Abebe M. [40] found no association of HEV infection with pet ownership. Screening for $\mathrm{HCV}$ and HEV infection is rarely done in Egypt where HBV is the only hepatitis 
virus pregnant women are screened for, this is mainly due to the availability of effective preventive measures for the newborn in cases of maternal infection with HBV.

The limitations of this study were: we included all pregnant women in any gestational age, we measured HBsAG which does not differentiate acute or chronic infection (however, given the study inclusion criteria, this finding most likely indicated chronic carrier state.), also we measured HEV IgG which indicated a high past infection prevalence in the study area but we did not perform a confirmatory PCR test for the HEV RNA due to its high cost.

\section{Conclusion}

Viral hepatitis in pregnant women is a commonly encountered situation in Egypt. Although it seems that there are many improvements in the prevalence of different viruses in the country, hepatitis viral infections are still high enough to continue their preventive programs and health education, to protect the mothers and their fetuses from the hazardous effects of these serious infections.

\section{Conflicts of Interest}

The authors declare that they have no conflicts of interest.

\section{References}

[1] Rasheeda, C.A., Navaneethan, U. and Jayanthi, V. (2008) Liver Disease in Pregnancy and Its Influence on Maternal and Fetal Mortality-A Prospective Study from Chennai, Southern India. European Journal of Gastroenterology \& Hepatology, 20, 362-364. https://doi.org/10.1097/MEG.0b013e3282f246d6

[2] Stoszek, S.K., Abdel-Hamid, M., Saleh, D.A., et al. (2006) High Prevalence of Hepatitis E Antibodies in Pregnant Egyptian Women. Transactions of the Royal Society of Tropical Medicine and Hygiene, 100, 95-101. https://doi.org/10.1016/j.trstmh.2004.12.005

[3] Kumar, A., Beniwal, M., Kar, P., Sharma, J.B. and Murthy, N.S. (2004) Hepatitis E in Pregnancy. International Journal of Gynecology \& Obstetrics, 85, 240-244. https://doi.org/10.1016/j.ijgo.2003.11.018

[4] Purcell, R. and Emerson, S. (2005) Viral Hepatitis. In: Mendell, G.L., Douglas, R.G., Bennett, J.E. and Dolin, R., Eds., Menell, Douglas and Bennett's Principles and Practice of Infectious Diseases, 6th Edition, Elsevier/Churchill Livingstone, New York, 2204-2217.

[5] Sookian, S. (2006) Liver Disease during Pregnancy: Acute Viral Hepatitis. Annals of Hepatology, 5, 231-236. https://doi.org/10.1016/S1665-2681(19)32019-8

[6] Alter, M.J. (2003) Epidemiology of Hepatitis B in Europe and Worldwide. Journal of Hepatology, 39, 64-69. https://doi.org/10.1016/S0168-8278(03)00141-7

[7] Mast, E.E., Weinbaum, C.M., Fiore, A.E., Alter, M.J., Bell, B.P., Finelli, L., Rodewald, L.E., Douglas Jr., J.M., Janssen, R.S. and Ward, J.W. (2006) A Comprehensive Immunization Strategy to Eliminate Transmission of Hepatitis B Virus Infection in the United States: Recommendations of the Advisory Committee on Immunization Practices (ACIP) Part II: Immunization of Adults. MMWR Recommendations and Reports, 55, 1-3. 
[8] Chowdhury, S.D. and Eapen, C.E. (2009) Perinatal Transmission of Hepatitis B. Hepatitis B Annual, 6, 80-88. https://doi.org/10.4103/0972-9747.76906

[9] Libbus, M.K. and Phillips, L.M. (2009) Public Health Management of Perinatal Hepatitis B Virus. Public Health Nursing, 26, 353-361. https://doi.org/10.1111/j.1525-1446.2009.00790.x

[10] Jara, P. and Bruguera, M. (2008) Hepatitis B in Pregnant Women and Children. Enfermedades Infecciosas y Microbiología Clínica, 26, 66-70. https://doi.org/10.1016/S0213-005X(08)76521-2

[11] Spera, A.M., Eldin, T.K., Tosone, G. and Orlando, R. (2016) Antiviral Therapy for Hepatitis C: Has Anything Changed for Pregnant/Lactating Women? World Journal of Hepatology, 8, 557-565. https://doi.org/10.4254/wjh.v8.i12.557

[12] Joint Panel from the American Association for the Study of Liver Diseases and the Infectious Diseases Society of America (2017) Recommendations for Testing, Managing, and Treating Hepatitis C. https://www.hcvguidelines.org/

[13] Benova, L., Mohamoud, Y.A., Calvert, C. and Abu-Raddad, L.J. (2014) Vertical Transmission of Hepatitis C Virus: Systematic Review and Meta-Analysis. Clinical Infectious Diseases, 59, 765-773. https://doi.org/10.1093/cid/ciu447

[14] Huang, Q., Hang, L., Zhong, M., Gao, Y., Luo, M. and Yu, Y. (2016) Maternal HCV Infection Is Associated with Intrauterine Fetal Growth Disturbance. Medicine, 95, 1-7. https://doi.org/10.1097/MD.0000000000004777

[15] El-Zenati, F. and Way, A. (2008) Knowledge and Prevalence of Hepatitis C. Egypt Demographic and Health Survey. https://dhsprogram.com/pubs/pdf/FR220/FR220.pdf

[16] Ministry of Health, Egypt, El-Zanaty and Associates, Egypt, ICF International (2015) Egypt Health Issues Survey. Ministry of Health and ICF International, Cairo, Egypt and Rockville, MD.

[17] Khater, M. (2016) WHO Recognizes Egypt's Efforts in the Combating Hepatitis C. Daily News Egypt.

[18] Patra, S., Kumar, A., Trivedi, S.S., Puri, M. and Sarin, S.K. (2007) Maternal and Fetal Outcomes in Pregnant Women with Acute Hepatitis E Virus Infection. Annals of Internal Medicine, 147, 28-33. https://doi.org/10.7326/0003-4819-147-1-200707030-00005

[19] Singh, S., Mohanty, A., Joshi, Y.K., Deka, D., Mohanty, S. and Panda, S.K. (2003) Mother to Child Transmission of Hepatitis E Virus Infection. The Indian Journal of Pediatrics, 70, 37-39. https://doi.org/10.1007/BF02722743

[20] Krain, L.J., Atwell, J.E., Nelson, K.E. and Labrique, A.B. (2014) Fetal and Neonatal Health Consequences of Vertically Transmitted Hepatitis E Virus Infection. The American Journal of Tropical Medicine and Hygiene, 90, 365-370. https://doi.org/10.4269/ajtmh.13-0265

[21] Khuroo, M.S. (2011) Discovery of Hepatitis E: The Epidemic Non-A, Non-B Hepatitis 30 Years down the Memory Lane. Virus Research, 161, 3-14. https://doi.org/10.1016/j.virusres.2011.02.007

[22] Nan, Y., Wu, C., Zhao, Q. and Zhou, E.-M. (2017) Zoonotic Hepatitis E Virus: An Ignored Risk for Public Health. Frontiers in Microbiology, 8, 2396. https://doi.org/10.3389/fmicb.2017.02396

[23] Pérez-Gracia, M.T., Suay, B. and Mateos-Lindemann, M.L. (2014) Hepatitis E: An Emerging Disease. Infection, Genetics and Evolution, 22, 40-59.

https://doi.org/10.1016/j.meegid.2014.01.002 
[24] Shahzad, F., Atiq, M., Ejaz, S. and Hameed, S. (2001) Hepatitis E: Review of a Disease Endemic in Pakistan. Journal of Pakistan Medical Association, 51, 166-169.

[25] McAtee, C.P., Zhang, Y., Yarbough, P.O., Fuerst, T.R., Stone, K.L., Samander, S. and Williams, K.R. (1996) Purification and Characterization of a Recombinant Hepatitis E Protein Vaccine Candidate by Liquid Chromatography-Mass Spectrometry. Journal of Chromatography B: Biomedical Sciences and Applications, 685, 91-104. https://doi.org/10.1016/0378-4347(96)00143-0

[26] Kim, J.H., Nelson, K.E., Panzner, U., Kasture, Y., Labrique, A.B. and Wierzba, T.F. (2014) A Systematic Review of the Epidemiology of Hepatitis E Virus in Africa. BMC Infectious Diseases, 14, Article No. 308.

https://doi.org/10.1186/1471-2334-14-308

[27] Kirkpatrick, L.A. and Feeney, B.C. (2013) A Simple Guide to IBM SPSS Statistics for Version 20.0. Student Ed. Wadsworth, Cengage Learning, Belmont, CA.

[28] Blach, S., Zeuzem, S., Manns, M., et al. (2016) Global Prevalence and Genotype Distribution of Hepatitis C Virus Infection in 2015: A Modelling Study. The Lancet Gastroenterology and Hepatology, 2, 161-176. https://doi.org/10.1016/S2468-1253(16)30181-9

[29] Sharma, P. and Steele, R.W. (2011) Pediatric Hepatitis B.

[30] El-Zayadi, A. (2007) Hepatitis B Virus Infection the Egyptian Situation. Arab Journal of Gastroenterology, 8, 94-98.

[31] Zahran, K.M., Badary, M.S., Agban, M.N. and Abdel Aziz, N.H.R. (2010) Pattern of Hepatitis Virus Infection among Pregnant Women and Their Newborns at the Women's Health Center of Assiut University, Upper Egypt. International Journal of Gynecology \& Obstetrics, 111, 171-174. https://doi.org/10.1016/j.ijgo.2010.06.013

[32] EL-Shabrawi, M., Farouk, M., Salah El Din, M., et al. (2013) Prevalence of Hepatitis B Virus Infection among Egyptian Pregnant Women-A Single Center Study. International Journal of TROPICAL DISEASE \& Health, 3, 157-168. https://doi.org/10.9734/IJTDH/2013/3276

[33] Doss, W., Mohamed, M.K., Esmat, G., et al. (2008) Egyptian National Control Strategy for Viral Hepatitis 2008-2012. Arab Republic of Egypt, Ministry of Health and Population, National Committee for the Control of Viral Hepatitis.

[34] El-Shety, G., Ibrahim, A., kamel, H., Kelany, Y., et al. (2014) Seroprevalence of Subclinical Hepatitis E Infection among Pregnant Women in Rural Egyptian Areas. Asian Academy of Management Journal, 12, 162-178.

[35] Abdel-Hamid, M., Stoszek, S.K., Saleh, D.A., et al. (2005) High Prevalence of Hepatitis E Antibodies in Pregnant Egyptian Women. Transactions of The Royal Society of Tropical Medicine and Hygiene, 100, 95-101. https://doi.org/10.1016/j.trstmh.2004.12.005

[36] Gad, Y.Z., Mousa, N., Shams, M. and Elewa, A. (2011) Seroprevalence of Subclinical HEV Infection in Asymptomatic, Apparent Healthy Pregnant Women in Dakahlya Governorate, Egypt. Asian Journal of Transfusion Science, 5, 136-139. https://doi.org/10.4103/0973-6247.83238

[37] Huang, F., Ma, T., Li, L., Zeng, W. and Jing, S. (2013) Low Seroprevalence of Hepatitis E Virus Infection in Pregnant Women in Yunnan, China. The Brazilian Journal of Infectious Diseases: An Official Publication of the Brazilian Society of Infectious Diseases, 17, 716-717. https://doi.org/10.1016/j.bjid.2013.02.006

[38] Lindemann, M.L.M., Gabilondo, G., Romero, B., de la Maza, O.M.S. and PeÂrezGracia, M.T. (2010) Low Prevalence of Hepatitis E Infection among Pregnant Women in Madrid, Spain. Journal of Medical Virology, 82, 1666-1668. 
https://doi.org/10.1002/jmv.21840

[39] Renou, C., Gobert, V., Locher, C., Moumen, A., Timbely, O., Savary, J., et al. (2014) Prospective Study of Hepatitis E Virus Infection among Pregnant Women in France. Virology Journal, 11, Article No. 68.

https://doi.org/10.1186/1743-422X-11-68

[40] Abebe, M., Ali, I., Ayele, S., Overbo, J., Aseffa, A. and Mihret, A. (2017) Seroprevalence and Risk Factors of Hepatitis E Virus Infection among Pregnant Women in Addis Ababa, Ethiopia. PLoS ONE, 12, e0180078. https://doi.org/10.1371/journal.pone.0180078

[41] Kafando, F., Ouermi, D., Gnoula, C., Florencia, D.W., Obiri-Yeboah, D., Rebeca, C.T., et al. (2016) Hepatitis E in Pregnant Women at the Saint Camille Hospital of Ouagadougou in Burkinafaso: Prevalence and Infection Risk Factors. International Journal of Recent Advances in Multidisciplinary Research, 3, 1885-1888. 